\title{
The Impacts of Automation on Present Weather-Type Observing Capabilities across the Conterminous United States
}

\author{
Scott D. LAndolt, Joshua S. Lave, Darcy Jacobson, And AndRew Gaydos \\ National Center for Atmospheric Research, Boulder, Colorado \\ STEPHANIE DiVito \\ William J. Hughes Technical Center, Federal Aviation Administration, Atlantic City, New Jersey \\ DANIEL PORTER \\ National Weather Service, Albuquerque, New Mexico
}

(Manuscript received 3 July 2019, in final form 18 October 2019)

\begin{abstract}
In the 1990s, the National Weather Service and the Federal Aviation Administration began deploying the Automated Surface Observing Systems (ASOS). These systems provided the capability to report real-time weather observations, including some types of present weather, as frequently as once every minute. Over 900 of these ASOS stations were installed across the United States, replacing most of the human observers. Despite the benefits offered, many issues were noted, including the inability to discern and report certain precipitation types, particularly drizzle, freezing drizzle, and ice pellets. These and other issues resulted in human observers being retained at roughly 130 ASOS airport locations around the country where high-quality weather observations are essential because of air traffic volume or other factors. The human observers at these locations work in conjunction with the ASOS, manually augmenting the automated weather observations when the ASOS provides erroneous data or when an ASOS observation is missing. To assess the impact of automation on present weather observations, the differences in present weather reports for two decades will be highlighted: 1979-88 (when only human observers reported the present weather observations) and 2005-14 (after the full ASOS network became operational). Comparisons between the decades will be further analyzed to determine the differences at the ASOS locations at which human observers were retained in the later decade, as well as the ASOS locations at which no humans were retained. Both the positive and negative impacts of automation, with an emphasis on aviation impacts, are presented.
\end{abstract}

\section{Introduction}

Meteorological observations have become increasingly important to aviation safety over the past century, especially with the dawn of the aviation era and the introduction of numerical weather prediction models. Humans initially provided these observations in the early decades of the twentieth century, but, as technology advanced, sensors were developed that could autonomously take many of the same types of observations. As these sensors became more prevalent, human weather observers began to rely on them for the basic observations (temperature, wind, etc.) while they focused on the more subjective observations (cloud cover, visibility, etc.).

Corresponding author: Scott Landolt, landolt@ucar.edu
In the 1960s and 1970s, some of the first automated systems were tested and deployed at various airports. The Automated Meteorological Observing System (AMOS) and Remote Automated Meteorological Observing System (RAMOS) could measure the more basic variables of temperature, dewpoint temperature, wind speed and direction, and pressure [National Oceanic and Atmospheric Administration (NOAA; NOAA 1981)]. As technology advanced, more sophisticated sensors were developed that could provide more subjective observations. The Automated Observation (AUTOB), developed in the early 1970s, provided additional capabilities to measure sky condition and visibility. In the 1980s, the first Automated Weather Observing System (AWOS) was developed, establishing a standard for the weather parameters reported (FAA 1989). They operated 
completely autonomously with little to no human intervention and increased the frequency of weather observation updates. While almost 2000 AWOS stations are in use today, and more are added every year, very few of them have the ability to provide observations of precipitation type because there is no formal requirement for them to do so.

In the 1990s, the National Weather Service (NWS) and the Federal Aviation Administration (FAA) began installation of the Automated Surface Observing Systems (ASOS) at airports around the country (NOAA 1998). The U.S. Department of Defense (DoD) also installed a small number of these stations at several U.S. Air Force and U.S. Navy bases. These systems serve as both weather observation sites and as the primary U.S. climatological observing network, replacing many of the human observers and sensors at sites established in the 1960s and 1970s.

In its current state, the ASOS has the capabilities of the previous automated systems plus the ability to make limited automated determinations of precipitation type-namely, rain, snow, and freezing rain. Rain (RA) and snow (SN) observations are derived from the Light Emitting Diode Weather Identifier (LEDWI) present weather sensor. The LEDWI sensor is an optical-based sensor and operates on the principle that any type of precipitation will cause a scintillation signal in the optical beam that can be uniquely associated with either rain or snow (NOAA 1998).

The ASOS identifies freezing rain (FZRA) using a combination of the LEDWI, ambient air temperature, and the Goodrich Sensor Systems, Inc., model 872C3 icing detector, hereinafter referred to as the icing sensor. ASOS will report freezing rain when the LEDWI reports RA or unknown precipitation (UP), the current ice accretion exceeds $0.005 \mathrm{in} .(0.127 \mathrm{~mm})$, the current ice accretion exceeds the minimum accretion since the sensor was last declared operational or during the past $15 \mathrm{~min}$, whichever is less, by $0.002 \mathrm{in} .(0.05 \mathrm{~mm})$, and the current 5-min ambient temperature is less than $37^{\circ} \mathrm{F}$ $\left(3^{\circ} \mathrm{C}\right)$ (NOAA 1998).

Any precipitation type that is not classifiable by the ASOS will be reported as UP. This can happen in the case of mixed-phase precipitation (the ASOS cannot discern the different precipitation types in a mixed precipitation event) or when precipitation is making a transition from one type to another. This can also happen if the precipitation signal is near the detection threshold of the LEDWI sensor. If the precipitation is too light to be detected by the ASOS, which can occur with drizzle, freezing drizzle, or light snow, the weather may be reported as "clear" by the ASOS. These issues are mitigated at airports that still maintain a human observer who can augment and correct the automated observations.

The ASOS sites are classified into service levels (FAA 2017) that help to identify whether a human observer exists at the site and the extent to which they can modify the ASOS observations. Service level A and B airports, for example, have full-time human contract weather observers (CWOs) to report the various weather conditions $24 \mathrm{~h}$ per day for 7 days per week. These CWOs are located at nearly 130 ASOS sites (or $12 \%$ of ASOS locations) around the country. They can modify the ASOS observations, including precipitation type, in the event ASOS misses or erroneously reports the weather conditions. Service level C airports (approximately 34\% of ASOS locations) have observers that can provide augmented observations but on a very limited basis. Observers at these airports are typically FAA air traffic control (ATC) personnel trained to take weather observations, providing observations during the day or during peak air traffic periods. They are not permitted to leave the FAA tower and can only provide weather observations, as time permits, during their regular ATC duties. Last are service level D airports, which are the most numerous (approximately 54\% of ASOS locations). These airports have no CWOs or ATC personnel and thus have no capability to regularly augment ASOS observations, although human augmentation occasionally occurs at these sites for unknown reasons.

With the removal of human observers at many of the surface observing locations and the growing reliance on the ASOS for automated weather observations, climatologists became increasingly concerned about the impact automated observations from the ASOS could have on climate records. After the network of ASOS systems was installed, climatologists began comparing the automated data with other established collocated measurement references. Temperature measurements from ASOS, for example, have been studied by a number of different groups (Guttman and Baker 1996; Sun et al. 2005; Lin and Hubbard 2004; Kessler et al. 1993; Gall et al. 1992). Almost all of the studies noted warm biases in the ASOS measurements of up to $0.3^{\circ} \mathrm{F}\left(0.1^{\circ} \mathrm{C}\right)$.

Sky-cover and ceiling-height measurements from the ASOS were also analyzed. Dai et al. (2006), Sun et al. (2007), Warren et al. (2007), and Free and Sun (2014) noted differences ranging from cloud-ceiling-height errors to inhomogeneity errors in the long-term cloudcover record, all of which began with the introduction of the ASOS. Doesken et al. (2002) discussed issues with the ASOS ceiling measurements but also investigated differences in dewpoint, precipitation, wind, and visibility measurements. One of the deficiencies they noted on the ASOS was the loss of information on "the frequency and 
duration of various weather types such as snow [pellets] and ice pellets, and freezing precipitation."

Reeves (2016) examined the impacts of augmented versus nonaugmented ASOS locations over a 15 -yr period and noted that ice pellets and freezing drizzle reports differed significantly between augmented and nonaugmented sites. Elmore et al. (2015) also noted an underestimate of ice pellet reports at the nonaugmented sites in the later decade.

To more fully assess the impact of automated precipitation-type detection on the current present weather reporting capabilities, a study was undertaken to compare Surface Aviation Observation (SAO) and Meteorological Aerodrome Report (METAR) observations of various pristine (i.e., non-mixed-phase) present weather types (rain, snow, drizzle, ice pellets, freezing rain, and freezing drizzle) from periods before and after the ASOS network was deployed around the United States. SAO observations were the standard type of weather observation report in the United States prior to the 1990s. In the mid-1990s, the United States switched to using the METAR standard. Of the 1367 SAO locations in the 1980s, just under one-half (610) were converted to ASOS locations in the 1990s (NOAA 2019). Data from these locations were used in this study to allow for a more direct comparison of observations between the two decades. Additional ASOS locations that were not SAO locations in the 1980s will also be included and their contributions to present weather-type observations highlighted. AWOS sites were not used in this study because of the inability for most of them to report present weather conditions.

Two 10-yr periods were examined: 1 January 197931 December 1988 (hereinafter referred to as the early decade) and 1 January 2005-31 December 2014 (hereinafter referred to as the later decade). The precipitation-type observations in the early decade were only reported by human observers, whereas the later decade was characterized by both the ASOS and human-augmented observations of present weather. Precipitation reports where mixedphase precipitation was occurring were excluded from this study because of the ASOS's inability to report more than one precipitation type (at nonhuman-augmented ASOS locations). Precipitation intensities (light, moderate, and heavy) were also not analyzed as part of this study.

\section{Method}

Data for this study were retrieved from the Research Applications Laboratory (RAL) surface observation data archive at the National Center for Atmospheric Research (NCAR; NCAR 2018). This archive is a collection of METAR, SAO, and other surface observations from around the world that is continuously updated via a live feed from NOAA. The archive spans decades, with observations from some stations dating back to the 1930s.

These surface observations can oftentimes contain errors that occur for many reasons, including observations incorrectly input by a human observer or a malfunctioning sensor that provides erroneous data that is not detected and removed by the automated quality control algorithms. To remove the more obvious errors in the data, a filtering algorithm was developed for each precipitation type (Table 1). The temperature and cloud-base thresholds were developed either by using existing protocols from the ASOS algorithm or by performing a statistical analysis of the data and accepting all data that fell within the 90th percentile. All METAR and SAO data were then processed through the algorithm to flag and remove observations that did not meet the specified criteria. For example, consider the following METAR from Key West, Florida, on 26 August 2005:

\section{KEYW 261705Z AUTO 18047G59KT 1/2SM SN BKN011 OVC018 24/ A2958}

Snow is the reported precipitation type, even though the temperature is $+24^{\circ} \mathrm{C}$. In this instance, the report likely should have been coded as "SQ" for squall, considering that the winds were gusting to $59 \mathrm{kt}\left(1 \mathrm{kt} \approx 0.51 \mathrm{~m} \mathrm{~s}^{-1}\right)$. Because the temperature exceeded the $3^{\circ} \mathrm{C}$ threshold for snow based on the snow filter shown in Table 1, the observation was removed.

Once the data were processed through the appropriate filter, an hourly analysis was performed. Multiple reports of each precipitation type occurring within each hour were removed such that only one report for each precipitation type per hour was counted. For example, if snow was reported individually three times in one hour, rain was reported individually two times and freezing rain and ice pellets were reported together once, only one report of rain and one report of snow would be counted for that hour. The freezing rain and ice pellet report would not be counted because it occurred as mixed-phase precipitation and this study focused solely on non-mixed-phase precipitation types. This eliminated the impact that multiple METAR precipitationtype observations per hour [e.g., special (unscheduled) reports (SPECIs) or METARs that occur at off-hour reporting times because of changing weather conditions] would have on overreporting the final counts of each observation. It is important to point out that these 
TABLE 1. Filters applied to METAR and SAO observations.

\begin{tabular}{|c|c|}
\hline Precipitation Type & Filters \\
\hline Rain & $\begin{array}{l}\text { Cloud coverage must be scattered, broken, } \\
\text { or overcast } \\
\text { Wet-bulb temperature } \geq 0{ }^{\circ} \mathrm{C} \\
\text { Dewpoint depression } \leq 10^{\circ} \mathrm{C}\end{array}$ \\
\hline Snow & $\begin{array}{l}\text { Cloud coverage must be broken or overcast } \\
\text { Ambient air temperature must be } \leq 3^{\circ} \mathrm{C} \\
\text { Dewpoint depression } \leq 5^{\circ} \mathrm{C}\end{array}$ \\
\hline Drizzle & $\begin{array}{l}\text { Cloud coverage must be overcast } \\
\text { Wet-bulb temperature } \geq 0^{\circ} \mathrm{C} \\
\text { Dewpoint depression } \leq 3^{\circ} \mathrm{C} \\
\text { Cloud-base height }<600 \mathrm{~m}(2000 \mathrm{ft})\end{array}$ \\
\hline Freezing rain & $\begin{array}{l}\text { Cloud coverage must be scattered, broken, } \\
\text { or overcast } \\
\text { Wet-bulb temperature } \leq 0^{\circ} \mathrm{C} \\
\text { Dewpoint depression } \leq 10^{\circ} \mathrm{C}\end{array}$ \\
\hline Freezing drizzle & $\begin{array}{l}\text { Cloud coverage must be overcast } \\
\text { Wet-bulb temperature } \leq 0^{\circ} \mathrm{C} \\
\text { Dewpoint depression } \leq 3^{\circ} \mathrm{C} \\
\text { Cloud-base height }<600 \mathrm{~m}(2000 \mathrm{ft})\end{array}$ \\
\hline Ice pellets & $\begin{array}{l}\text { Cloud coverage must be broken or overcast } \\
\text { Wet-bulb temperature } \leq 4^{\circ} \mathrm{C}\end{array}$ \\
\hline
\end{tabular}

counts are not equivalent to the total hours of each reported precipitation type. Rather, the values shown are the total number of hours containing at least one report for a given precipitation type each decade.

As a final step to filter out spurious, infrequent events (e.g., ice pellets reported by a buoy in the Gulf of Mexico), any station with a count of five or fewer events for the entire decade for a given type of precipitation was removed from the final dataset. This was done to remove events that slipped through the filters because other data required for the filters were missing, such as temperature and humidity or because the original observations had been parsed into the database incorrectly.

The data were then separated into airport service levels, and only data from the conterminous United States were used. Of the 118 service level A and B sites in the later decade, 117 of those sites existed as SAO sites in the early decade. Data from a total of 418 service level D sites were also included in the study. Of those 418 sites, 228 contained data from both the early and later decades, providing a method for analyzing locations that made the transition from human observers to no human engagement. Data from the other 190 service level D airports that did not exist in the earlier decade were also used to highlight the impacts of the expanded ASOS network in the later decade. Data from service level C sites are shown in the full ASOS location plots but were not analyzed individually in this study because the observations were augmented on a limited basis.

\section{Precipitation-type comparisons}

Maps will be presented to show the total hourly report counts for each precipitation type at each station. These maps will include the location and number of reports for each precipitation type for each 10 -yr period. Statistics highlighting the similarities and differences between the observations from the two periods will also be shown. Breakdowns of precipitation-type reports by airport service level will be highlighted as necessary to illustrate the impacts at sites where human observers are no longer available in the later decade (service level D airports) and where human observers have remained (service level A and B airports). Data used to generate these maps are summarized in Tables 2 and 3.

\section{a. Rain comparisons}

Rain can be reported in the SAO and METAR in various ways. For the purpose of this study, anytime an observation of RA, rain showers (SHRA), or thunderstorm (TSRA) was reported in the SAO or METAR, the observation was included in the rain category. Reports for which these specified observations were only in the vicinity (VC) and were not directly affecting the station were not included. Figure 1 shows the number of hourly reports of rain for the two decades at each station across the United States. Larger circles indicate higher counts for that SAO/METAR location. The relatively high number of rain reports in the central and eastern United States and along the coast in the Pacific Northwest for each decade are immediately noticeable, as is the observed minimum across the westcentral United States and desert Southwest.

One important difference between the two decades is the notable increase in the number of rain reports for the later decade. The earlier decade had nearly 1.8 million hourly rain reports while the later decade had over 1.5 million more reports for a total of nearly 3.4 million hourly rain reports. This represents an $89 \%$ increase in the number of reports in the later decade even though the number of ASOS sites in the later decade increased by only $30 \%$. To further explore this, the differences between the service level A and B airports and service level $\mathrm{D}$ airports between the decades are shown in Fig. 2. One obvious reason for the large increase in rain reports is the number of sites at service level D stations in the later decade that did not exist in the earlier decade. Of the nearly 1.6 million reports of rain at service level D stations, nearly one-half of those reports came from these 184 service level $\mathrm{D}$ sites added in the later decade. Interestingly, counts at the service level A and B sites between decades were similar, with just over 30000 more reports of rain in the later decade. However, of the 
TABLE 2. Number of sites for each airport service level per decade.

\begin{tabular}{lcccc}
\hline \hline Decade & $\begin{array}{c}\text { Service level } \\
\text { A and B }\end{array}$ & Service level C & Service level D & Total \\
\hline Early & 117 & 283 & 228 & 628 \\
Later & 118 & 315 & 418 & 851 \\
\hline
\end{tabular}

service level D sites with data in both decades, nearly 325000 more reports were noted at those service level D sites in the later decade. The remainder of the increase in the later decade was observed at the service level C airports.

Another reason for the difference in reports may be related to drought. The 1980s were characterized by drought conditions that occurred across the country (Namias 1982; Perkey et al. 1983; Weisman 1985; Kogan 1995) providing at least some explanation for the lowerfrequency reports of rain in the earlier decade (particularly at the service level A and B airports). However, drought conditions likely do not explain the dramatic increase in rain reports at the service level D airports. The more probable explanation is that not all stations were staffed $24 \mathrm{~h}$ a day at these locations (similar to the service level $\mathrm{C}$ airports in the later decade). To test that theory, the probability of precipitation occurrence was calculated for each hour of the day for service level A and B, and D airports for each decadal period (Fig. 3a). The probability of precipitation occurrence was calculated by summing the number of precipitation occurrences for every hour (0 to 23) over the course of each decade for each service level. Each hourly sum was then divided by the total number of reports to determine the probability of precipitation occurrence for each given hour in coordinated universal time (UTC).

The probability of precipitation occurring at any given hour is roughly the same for both service level
$\mathrm{A}$ and $\mathrm{B}$ and service level D locations in the later decade (solid and dashed red lines). The probability distribution for service level A and B airports in the early decade is also similar to the later decade (solid blue line) indicating that human observers in the early decade were taking observations of precipitation at times consistent with human observers in the later decade. The probability for service level D airports in the early decade, however, drops significantly during the overnight hours (dashed blue line) indicating a lack of observations at many of the locations during those hours.

To further test this, all available hourly weather reports for each early-decade service level D station were retrieved from the METAR database and the yearly number of hourly reports from each station was compared with the total number of annual hours. A percentage of total reports was then calculated for each year from 1979 to 1988 following the method in Cortinas et al. (2004). Unlike the Cortinas method, a stricter approach was utilized that required seven or more years of data from a given site to produce at least $90 \%$ of the maximum annual hourly reports before the station was considered a 24 -h weather reporting station. Additionally, some stations clearly showed that observers were deployed on a 24 -h basis at some point in the early decade as early years had percentages around $60 \%$ but increased to over $90 \%$ later in the decade and remained at $90 \%$ or higher for the remainder of the decade. In these instances, only the years from those sites that indicated that a $90 \%$ or higher percentage were included in the 24 -h weather reporting station.

Figure $3 \mathrm{~b}$ shows the results comparing the 24-h stations utilizing the method described above against the service level A and B stations in the later decade.

TABLE 3. Number of hourly observations of each precipitation type by decade and airport service level. Note that service levels were not assigned to sites until the later decade. Thus, the early-decade service-level classifications are based on the classification that the site was given when it was converted to an ASOS site.

\begin{tabular}{|c|c|c|c|c|}
\hline Precipitation type & Service level A and B & Service level C & Service level D & Total counts \\
\hline Rain (early decade) & 505595 & 825721 & 486593 & 1817909 \\
\hline Rain (later decade) & 537508 & 1259338 & 1596996 & 3393842 \\
\hline Snow (early decade) & 184045 & 274702 & 344941 & 803688 \\
\hline Snow (later decade) & 195388 & 311005 & 736728 & 1243121 \\
\hline Freezing rain (early decade & 4625 & 6924 & 5085 & 16634 \\
\hline Freezing rain (later decade) & 6200 & 18729 & 32456 & 57385 \\
\hline Drizzle (early decade) & 118518 & 208278 & 122775 & 449571 \\
\hline Drizzle (later decade) & 45892 & 7693 & 773 & 54358 \\
\hline Freezing drizzle (early decade) & 5443 & 8793 & 9061 & 23297 \\
\hline Freezing drizzle (later decade) & 4871 & 994 & 30 & 5895 \\
\hline Ice pellets (early decade) & 1354 & 1971 & 1666 & 4991 \\
\hline Ice pellets (later decade) & 1496 & 690 & 25 & 2211 \\
\hline
\end{tabular}




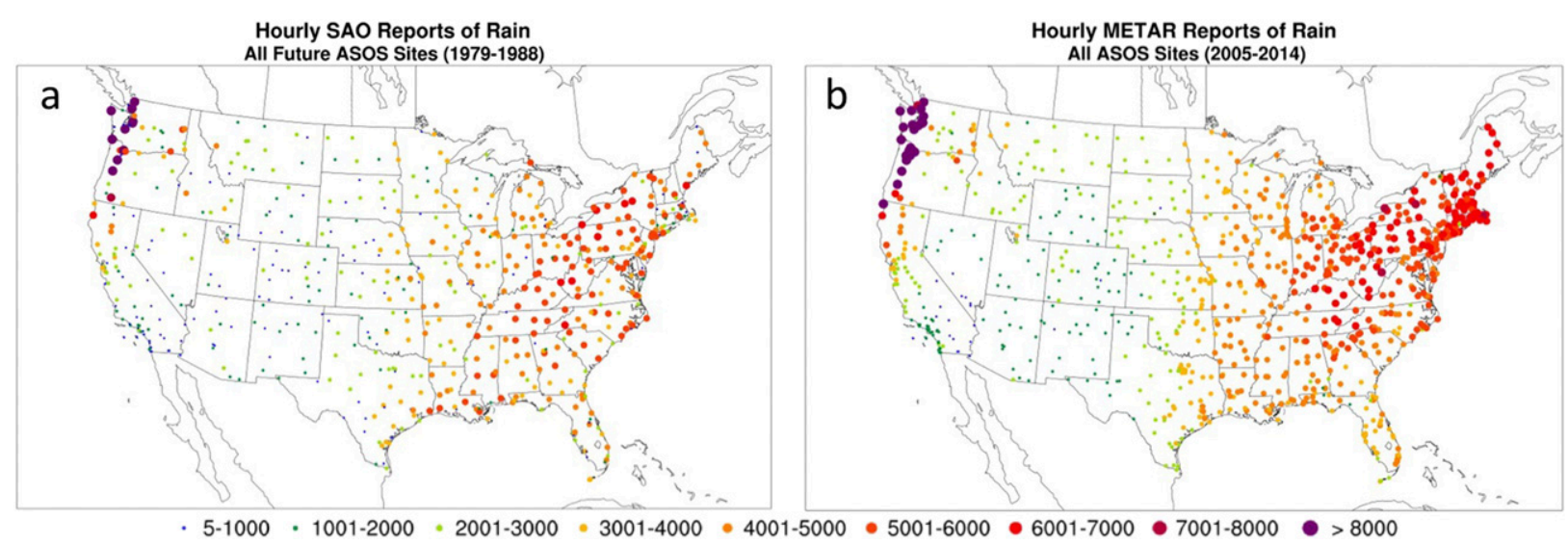

FIG. 1. (a) Number of rain reports from SAO observations across the United States for the early decade from 1 Jan 1979 to 31 Dec 1988. (b) Number of rain reports from METAR observations across the United States for the later decade from 1 Jan 2005 to 31 Dec 2014.

The probability of occurrence from the early decade matches much more closely to the later decade and provides the best probable explanation for the large increase in the later decade. A similar analysis calculating the probability of occurrence was done for the individual types of precipitation, and all types exhibited this same trend (except ice pellets, because of the significantly lower number of total pristine ice pellet reports).

\section{b. Snow comparisons}

As with rain observations, there are several ways snow can be reported in METAR observations. SN, snow
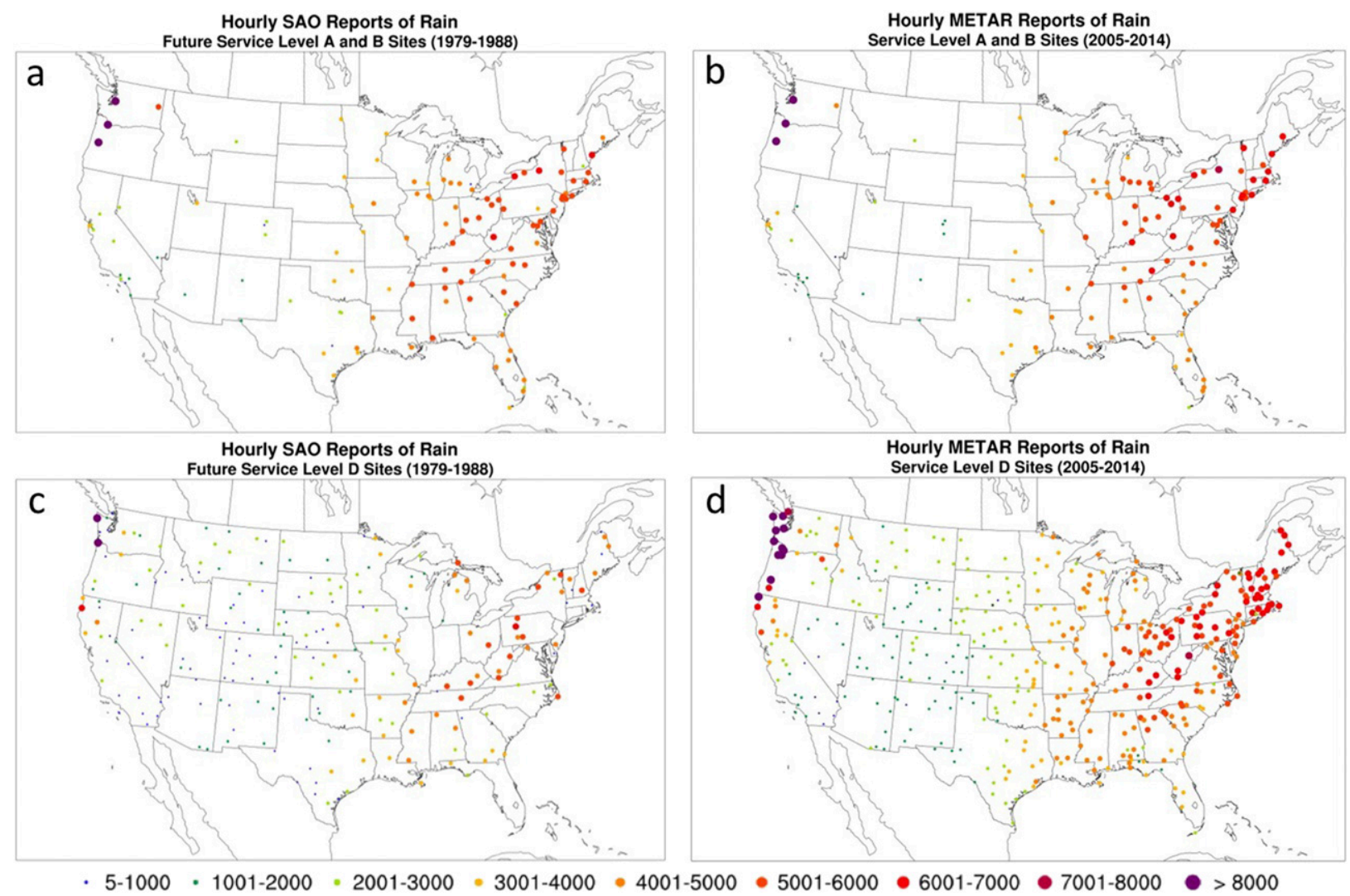

FIG. 2. Rain reports by station for (a) the early decade at future service level A and B sites, (b) the later decade at service level A and B sites, (c) the early decade at future service level D sites, and (d) the later decade at service level D sites. 

Normalized Hourly SAO/METAR Precipitation Report Distribution

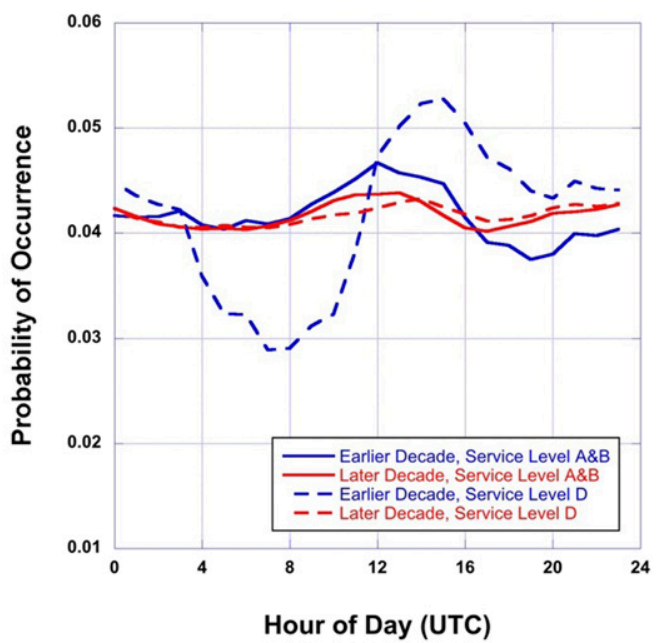

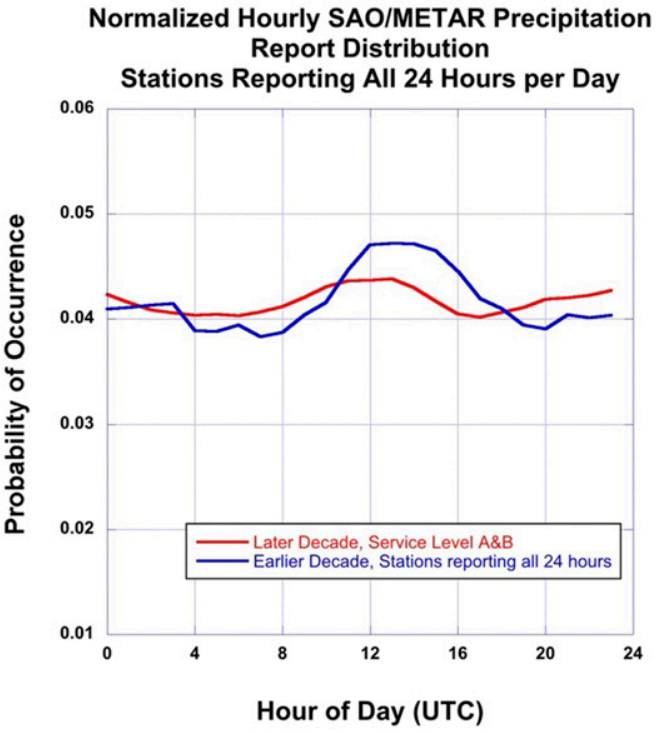

FIG. 3. (a) The probability of precipitation occurrence at service level A and B and service level D airports for each decade. The decrease in reports of RA for the overnight hours in the early decade at service level D airports indicates a lack of observations at some stations during those times. (b) The probability of precipitation occurrence at service level A and B airports in the later decade and at the stations that reported $24 \mathrm{~h}$ per day in the early decade.

showers (SHSN), and thunder snow (TSSN) were used in these comparisons. Observations that were reported as VC and thus not directly affecting the station were not included in the analysis. Figure 4 shows the snow comparisons between the two decadal periods. An overall gradient in the snow observations from north to south is evident for both decades. Similar to the trend shown in the rain data, an increase in the number of reports can be seen in the later decade. The earlier decade showed over 800000 reports, and the later decade had over 1.2 million reports, indicating a $55 \%$ increase in snow reports in the later decade even though the number of stations increased in the later decade by $30 \%$.

Figure 5 shows a four-panel view of the snow occurrences for the service level A and B and service level D airports for each decade. Again, relatively few differences in snow reports were observed at the service level $A$ and $B$ airports, with the later decade showing just over 11000 more reports than the earlier decade. Meanwhile, significant differences in snow reports were noted between the service level D airports for each of the two decades. Of the service level D sites with data in both

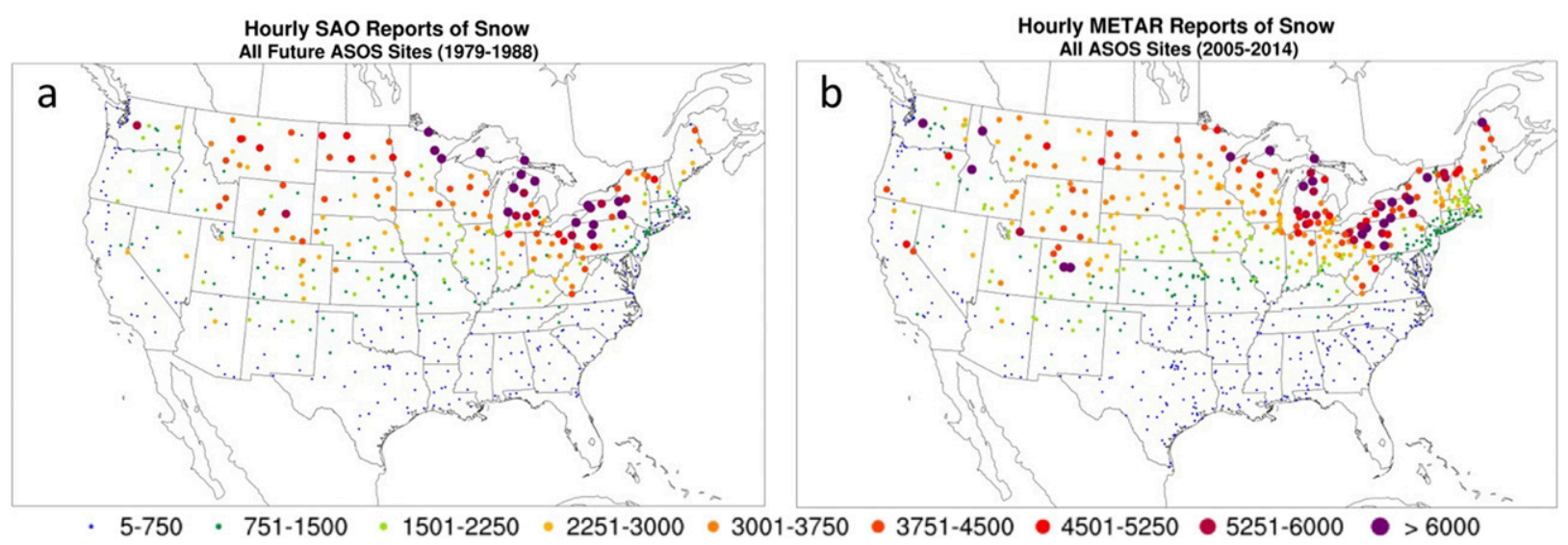

FIG. 4. (a) Number of snow reports from SAO observations across the United States for the early decade from 1 Jan 1979 to 31 Dec 1988. (b) Number of snow reports from METAR observations across the United States for the later decade from 1 Jan 2005 to 31 Dec 2014. 

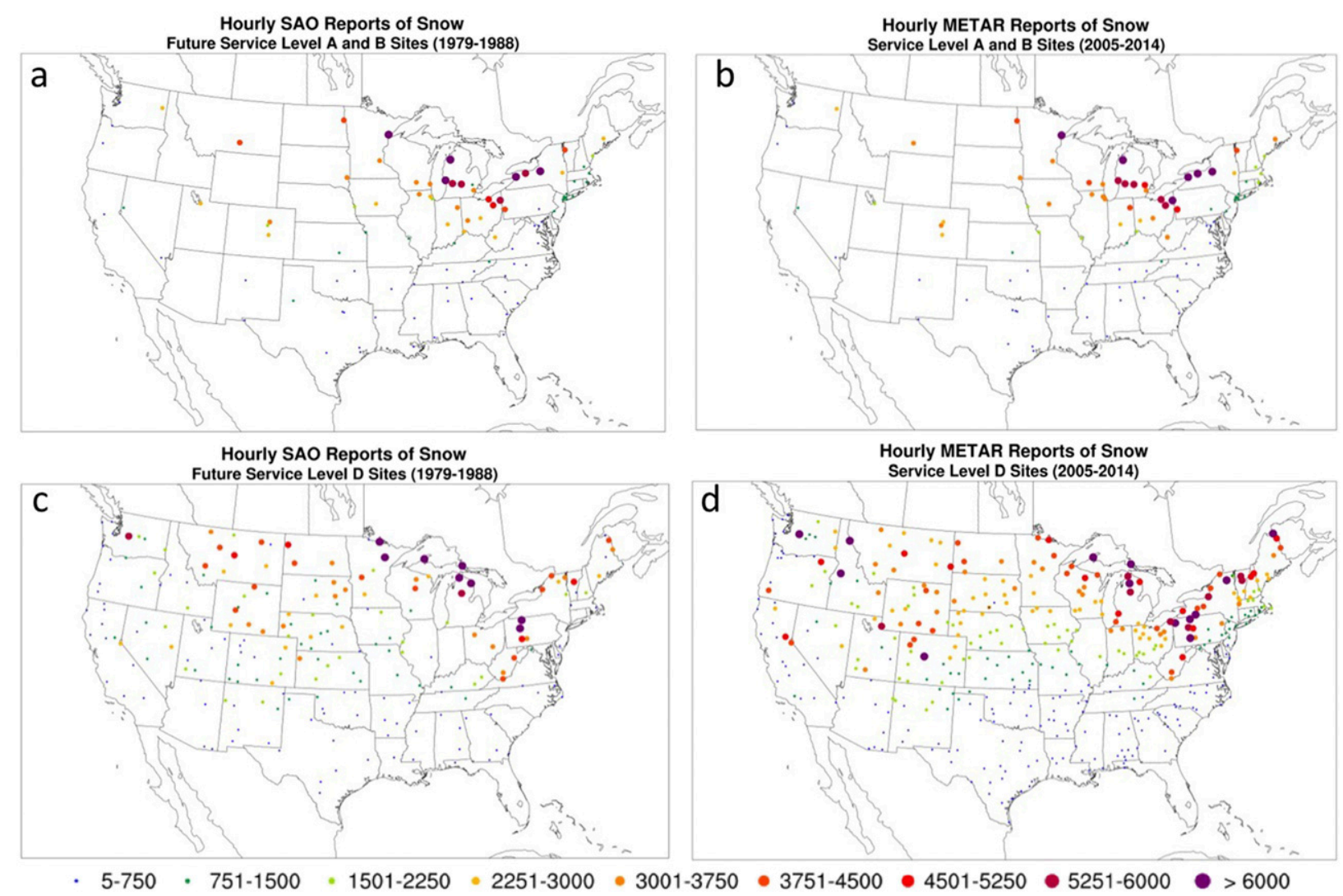

FIG. 5. Snow reports by station for (a) the early decade at future service level A and B sites, (b) the later decade at service level A and B sites, (c) the early decade at future service level D sites, and (d) the later decade at service level D sites.

decades, an increase of nearly 95000 reports was noted in the later decade. This is again attributed to an inconsistency of overnight observations in the earlier decade. Nearly 300000 reports came from the service level $\mathrm{D}$ sites with data only from the later decade. Also, as seen in Fig. 4, the number of snow reports in the later decade for service level D locations are much higher, particularly in some mountain locations throughout the west.

As evident in the rain and snow reports at service level $\mathrm{A}$ and $\mathrm{B}$ airports, a minimal difference in the number of reports was observed between the two decades. It is important to discern whether this is due to the human observers frequently augmenting the ASOS observations or because the LEDWI is able to detect rain and snow conditions with the same ability as a human observer. METARs, however, do not indicate when a human observer augments and changes the reported ASOS weather conditions. Therefore, to determine when a human observer modified the reported ASOS precipitation type, the original present weather report from the ASOS was recreated.

To do this, the raw 1-min observation data from each of the ASOS sites at service level A and B airports were downloaded from the NOAA National Centers for Environmental Information ASOS 1-min data archive (NOAA 2019). Software was developed to implement the ASOS precipitation-type algorithm as outlined in NOAA (1998) using the raw LEDWI data. This algorithm processed each minute of ASOS data to determine the present weather type that would have been reported if a METAR was generated. The METARs at service level A and B airports from the later decade were then analyzed and all instances of pristine rain and snow were identified and processed using the same methodology described in Table 1. Output from the algorithm was then date and time matched to the METARs containing rain and snow, and the present weather types were compared.

The final results depict the algorithm-derived present weather snow reports agreed with the METARs only $68 \%$ of the time. Similarly, the ASOS-derived present weather rain reports agreed with the METARs only $70 \%$ of the time. This indicates the human observers did not agree with the ASOS-generated precipitation types nearly one-third of the time and suggests the similarity of occurrences of rain and snow between the two 


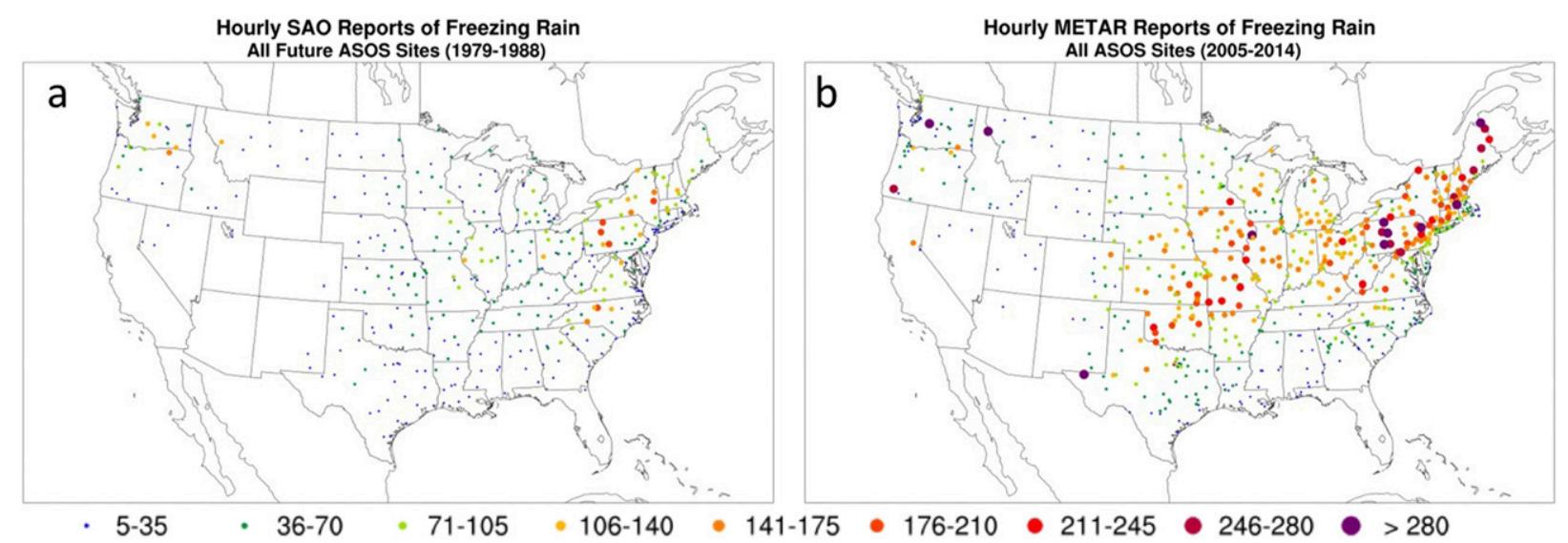

FIG. 6. (a) Number of freezing rain reports from SAO observations across the United States for the early decade from 1 Jan 1979 to 31 Dec 1988. (b) Number of freezing rain reports from METAR observations across the United States for the later decade from 1 Jan 2005 to 31 Dec 2014.

decades for the service level A and B airports is because the human observers are still present and frequently overriding the ASOS reports. Furthermore, rain and snow reports at service level D sites may be misreported (i.e., reported too frequently) by the ASOS for those precipitation types and might be another reason for the increase seen at the service level $\mathrm{D}$ sites in the later decade.

\section{c. Freezing rain comparisons}

Freezing rain is the only other precipitation type the ASOS can detect in an automated manner. Only reports of pristine FZRA from the METARs were used for this comparison. As stated earlier, ASOS will only report freezing rain when the icing sensor detects ice accretion, the LEDWI sensor observes rain, and the ambient temperature (5-min average) is less than $3^{\circ} \mathrm{C}$. As seen in Fig. 6, the later decade shows more than 3 times as many reports of freezing rain when compared to the earlier decade (approximately 16500 reports in the early decade and over 57000 reports in the later decade). This is a significant increase, especially considering there was only a $30 \%$ increase in the number of ASOS sites. While there is some expansion of the spatial coverage in the later decade, the actual number of reports clearly increases significantly across the New England region and into the Midwestern states. The distribution of the freezing rain reports in the later decade is also similar to that shown in Groisman et al. (2016).

Cortinas et al. (2004) performed a similar analysis for freezing rain and based their analysis of freezing rain events on a similar, though slightly longer, dataset from the earlier decade. The maxima reported in their analysis match similarly to those shown in the earlier decade in Fig. 6a, even though their analysis was based on the median annual hours, and the analysis shown here shows the total reports for the earlier period.

Observations from the later decade, however, show a significant increase in the number of reports, as well as an increase in the spatial coverage of FZRA. The later decade expands the domain of freezing rain reports westward into Colorado and New Mexico. A few outlier stations are noted in Texas, Oregon, Washington, and Idaho. These sites are relatively high-elevation sites that may frequently be located just below the melting layer, providing some explanation for the high number of reports. A large increase in the frequency of reports can also be seen as far west as Nebraska, Kansas, Oklahoma, and Texas. This significant increase is most likely attributed to the change in the observational network for detecting and reporting freezing rain. The ability of ASOS to detect ice accretion is the likely reason for the change. Before ASOS, human observers had to observe ice accreting on objects before they could report freezing rain conditions. This is especially true if ambient air temperature was at or just above freezing while the temperature of the ground or other surfaces was below freezing. This could have led to a delay in reporting freezing rain at the beginning of an event, the onset of which the ASOS would be better at detecting. It is also possible that observations of freezing rain were missed in the earlier decade because human observers were not present to report them, particularly during the overnight hours or at subhourly time scales. Cortinas et al. (2004), for example, showed a peak in freezing rain occurrences just before sunrise, providing further evidence than many of the freezing rain events in the earlier decade may have been missed at sites that did not have observers working during these hours. 


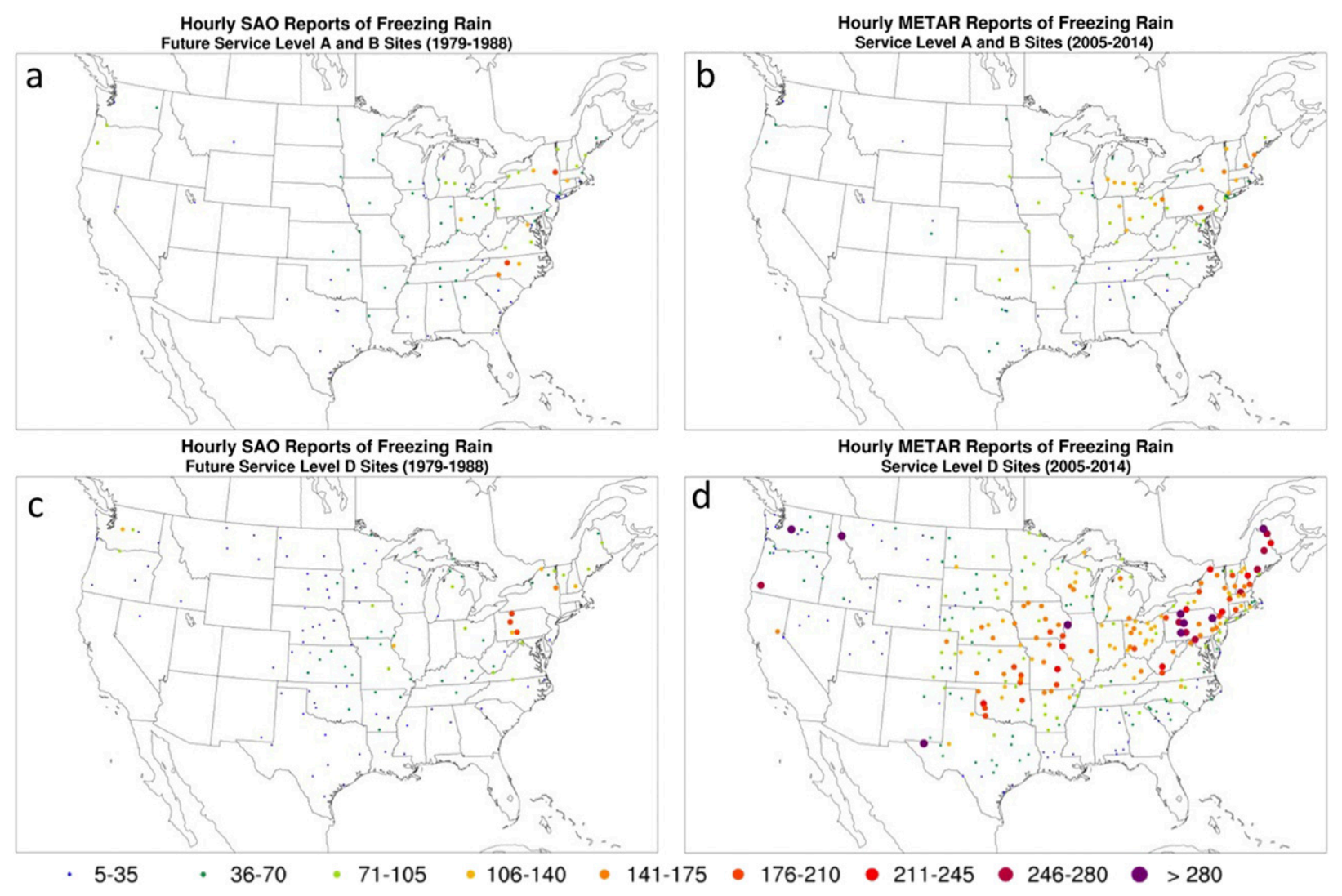

FIG. 7. Freezing rain reports by station for (a) the early decade at future service level A and B sites, (b) the later decade at service level A and B sites, (c) the early decade at future service level D sites, and (d) the later decade at service level D sites.

The differences between the reports in the earlier decade versus the later decade for service level A and B airports showed approximately 1600 more reports in the later decade (Fig. 7). As with the snow and rain observations, this was a small increase compared to the one observed at service level D airports. What is noticeable, however, is the change in location of where the reports were occurring. While the earlier decade showed most of the freezing rain reports occurring east of the Appalachian Mountains, the later decade showed most of the reports occurring in Indiana, Ohio, Pennsylvania, and areas north. The reason for this shift is unknown, though climate change may be one possibility. Interannual variability could also be a reason for the shift, especially since only 10 years are being analyzed before and after automation.

As mentioned previously, most of the pronounced changes occurred with the service level D airports (Fig. 7). Large increases in the number of freezing rain reports were observed in Oklahoma and places eastward through the Midwest and into New England. Service level D locations with data from both decades showed approximately 9500 more reports of freezing rain in the later decade. Nearly 18000 more reports were recorded at service level D locations that did not have data in the earlier decade. As stated earlier in the results from Cortinas et al. (2004), freezing rain occurs most frequently in the predawn hours. This likely provides some explanation for the observed increase in the later decade at service level D locations.

Regardless of the reasons, the implementation of automation has resulted in a significant increase in freezing rain reports. This is important considering the threat freezing rain poses to the safety of aircraft and the transportation industry, especially if observations of freezing rain in the earlier decade were missed. The increase in the number of freezing rain reports in the later decade indicates automation has helped improve the identification of freezing rain events and indicates many of these events could have been missed in the earlier decade. This has led to improved aviation safety by alerting pilots to these dangerous conditions and allowing them to cancel their planned flight, reroute their path to avoid the conditions, or take the necessary precautions (e.g., undergo a deicing process before takeoff) to minimize the hazard. 


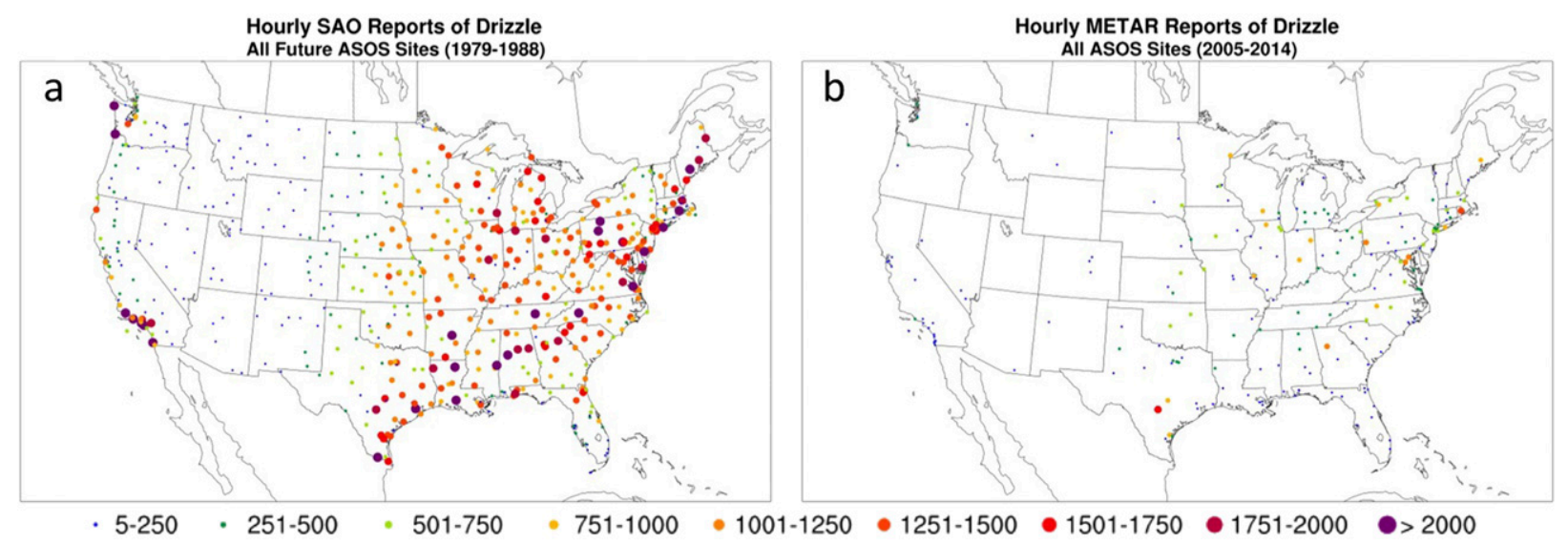

FIG. 8. (a) Number of drizzle reports from SAO observations across the United States for the early decade from 1 Jan 1979 to 31 Dec 1988. (b) Number of drizzle reports from METAR observations across the United States for for the later decade from 1 Jan 2005 to 31 Dec 2014.

\section{d. Drizzle comparisons}

Drizzle is most commonly reported in the METAR as DZ. Occasionally, drizzle showers (SHDZ) were also noted. Both were used for these comparisons. Nearly 450000 hourly reports of drizzle were observed in the earlier decade while just under 55000 hourly reports were observed in the later decade, accounting for a decrease of nearly $720 \%$ (Fig. 8). This decrease is even more striking considering that the number of ASOS sites increased by $30 \%$. One of the reasons for the decrease in the later decade is due to the way drizzle was reported in the earlier decade. Mist and drizzle were generally grouped together (R. Pierce 2019, personal communication). This included spray from the ocean, which explains some of the higher reports of drizzle in locations along the coastlines (southern California in particular). While drizzle is considered a precipitation type because the hydrometeors fall to the ground, mist is not given the hydrometeors remain suspended in the air (American Meteorological Society 2013). With the adoption of the METAR standard in the 1990 s, mist was redefined as an obscuration to visibility (intended to be indicative of small suspended water drops as it is defined in the AMS Glossary, although this is not always true) and was given its own classification (BR) in the METAR. Mist, in the later decade, was reported when the dewpoint depression was $2^{\circ} \mathrm{C}$ or less and visibility was between $5 / 8$ and $4 \mathrm{mi}(1 \mathrm{mi}=1.6 \mathrm{~km})$.

A comparison of the drizzle data between the two decades at service level A and B airports shows a large decrease (approximately 160\%) in drizzle observations (Fig. 9). As stated before, this is likely due to mist and drizzle now being separate, reportable phenomena and not because human observers are missing it. This is especially true considering other precipitation types like rain and snow have seen relatively little change in reports between the decades at service level A and B airports.

To further analyze the disparities in drizzle reports between decades, a map of the mist observations was created for the later decade (Fig. 10). As with the other weather-type reports, only pristine reports of mist were included and no more than one report of mist per hour was counted. A temperature filter was also applied to the data so only observations of mist at temperatures above freezing were included. Because mist has been redefined as an obscuration to visibility, the number of reports of mist is much greater in the later decade than in either the earlier or later decade of drizzle reports (shown in Fig. 8). However, Washington, California, and the eastern United States show significantly greater reports that correlate to the higher observations of drizzle in the earlier decade. This provides some additional evidence for the large decrease in the number of drizzle reports in the later decade and suggests that reports of drizzle in the earlier decade at some stations were dominated by mist.

Another prominent detail in Fig. 9 is the change in observations between the service level $\mathrm{D}$ airports. There were over 120000 drizzle reports at the service level D sites in the earlier decade while there were a mere 773 drizzle reports at the service level D sites in the later decade. As mentioned earlier, ASOS cannot report drizzle in an automated manner. It is unclear how the 773 reports of drizzle were generated at these sites, but the differences are very clear between decades at the service level $\mathrm{D}$ airports and when comparing the service level D airports with the service level A and B airports in the later decade. The lack of drizzle observations at the service level D sites is important to aviation because 

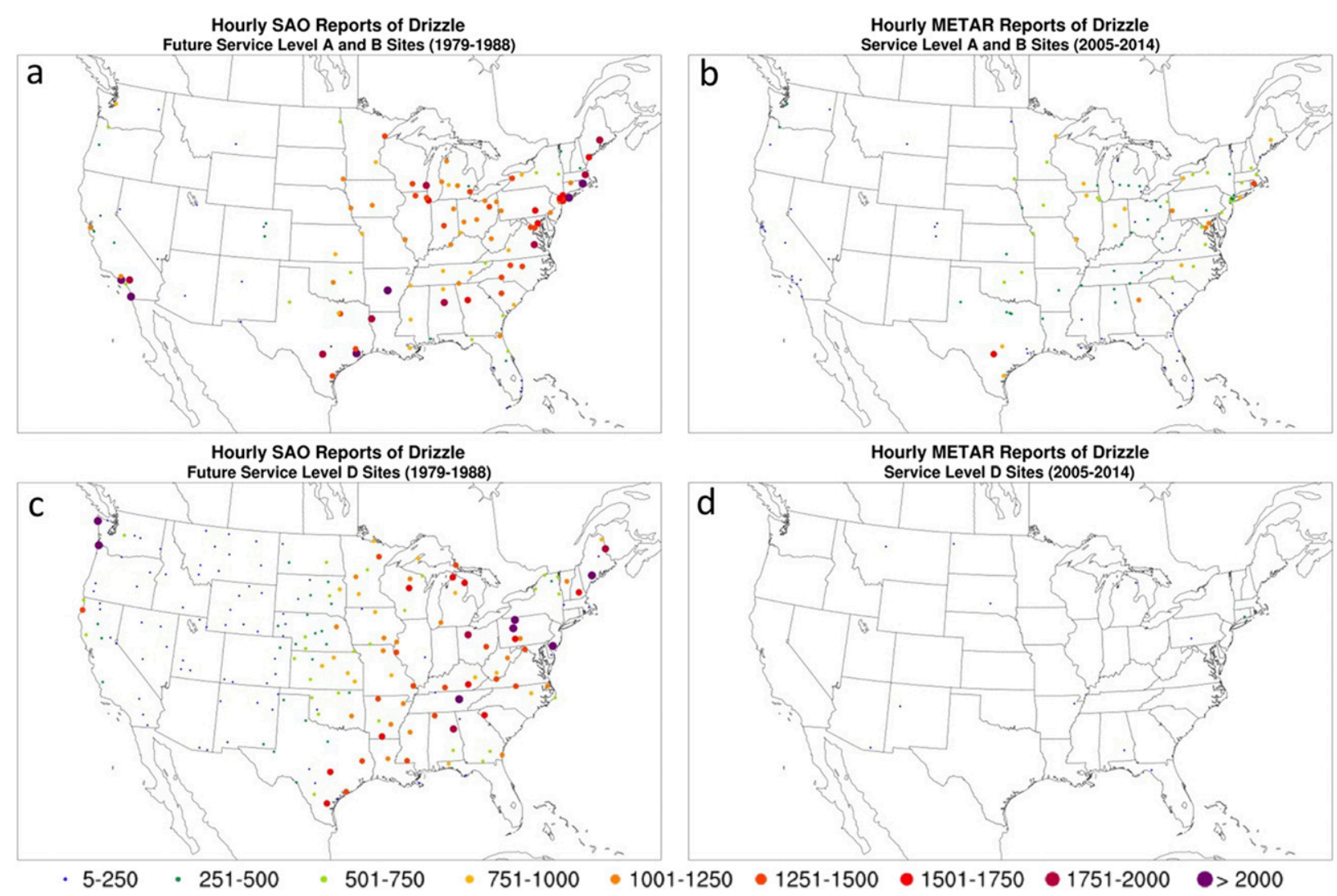

FIG. 9. Drizzle reports by station for (a) the early decade at future service level A and B sites, (b) the later decade at service level A and B sites, (c) the early decade at future service level D sites, and (d) the later decade at service level D sites.

drizzle can reduce visibility and can indicate freezing drizzle aloft. A lack of drizzle reports at these airports could result in aircraft flying into freezing drizzle aloft, conditions for which they may not be certified.

\section{e. Freezing drizzle comparisons}

Only reports of pristine freezing drizzle (FZDZ) from the METARs were used for this comparison. Similar to drizzle, freezing drizzle observations notably decreased in the later decade (Fig. 11). The earlier decade had a total of over 23000 hourly reports of freezing drizzle while the later decade had less than 6000 , indicating a $75 \%$ decrease in the number of freezing drizzle observations in the later decade. The distributions of freezing drizzle reports in the early decade match similarly to what Groisman et al. (2016) showed. They noted the automation of weather observations in the mid-2000s had significant impacts on the observations of freezing drizzle and resulted in them omitting the later years from their study. Not only have the number of freezing drizzle reports decreased (some significantly) in the later decade and in contrast to the increase in ASOS sites, but the areal coverage of freezing drizzle observations also decreased. As with drizzle, the primary reason for the reduction is attributed to the ASOS not having the capability to report freezing drizzle in an automated manner.

A relatively small difference in reports (fewer than 600) was again observed between decades at service level $\mathrm{A}$ and $\mathrm{B}$ airports with the later decade reporting

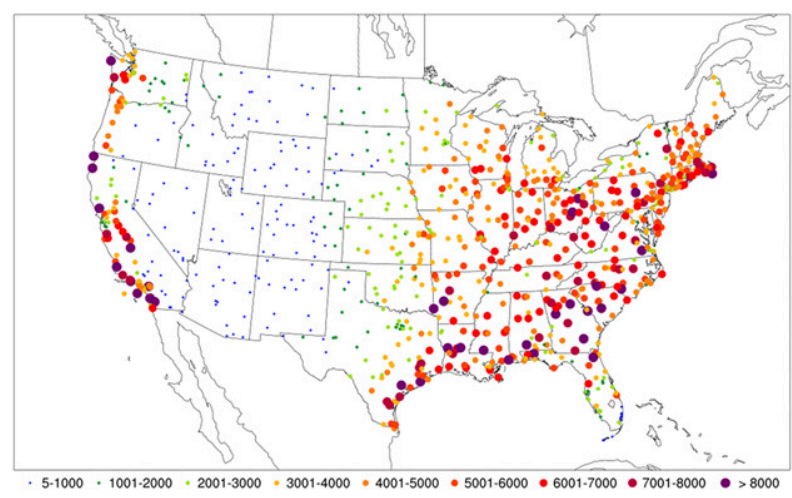

FIG. 10. Number of hourly mist reports at all ASOS locations for the later decade from 1 Jan 2005 to 31 Dec 2014. 

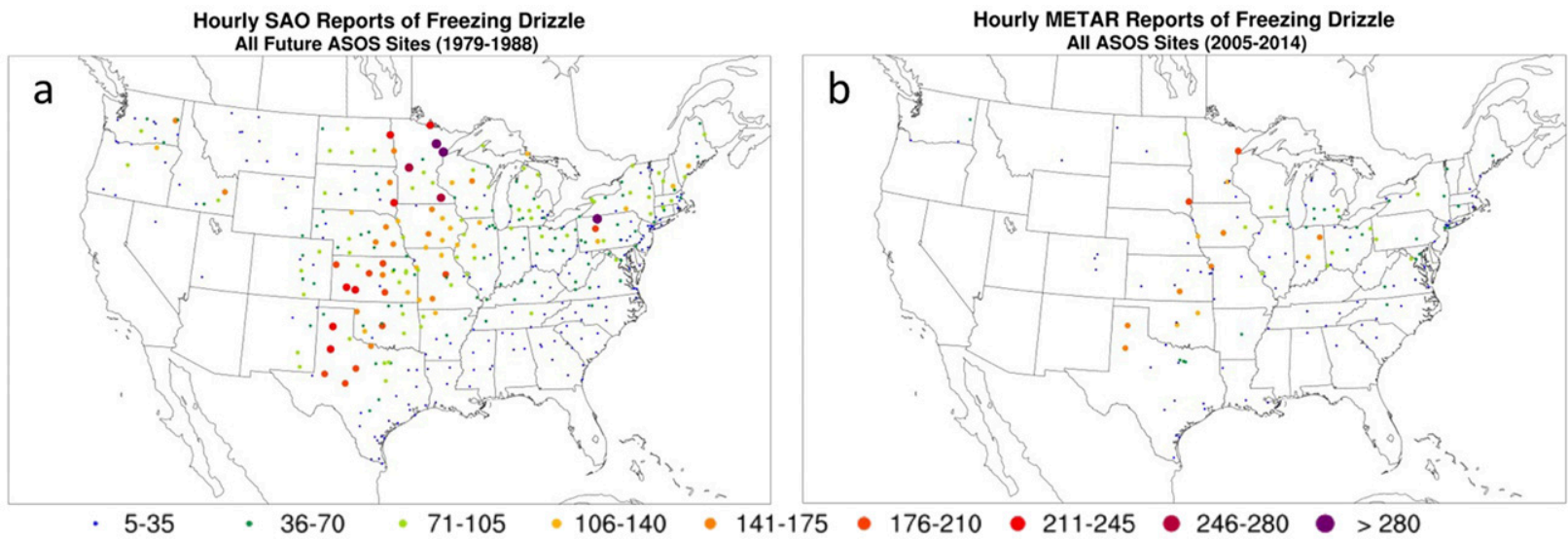

FIG. 11. (a) Number of freezing drizzle reports from SAO observations across the United States for the early decade from 1 Jan 1979 to 31 Dec 1988. (b) Number of freezing drizzle reports from METAR observations across the United States for the later decade from 1 Jan 2005 to 31 Dec 2014.

just over 5400 reports and the earlier decade reporting nearly 4900 reports. The greatest disparity in freezing drizzle observations is seen at service level D airports (Fig. 12). The elimination of the human observers at those airports has clearly had a significant impact on the climatological record for freezing drizzle and has likely created serious consequences to aviation. There were over 9000 reports of freezing drizzle at service level D airports in the earlier decade and only 30 reports in the later decade. This poses a significant risk to aviation
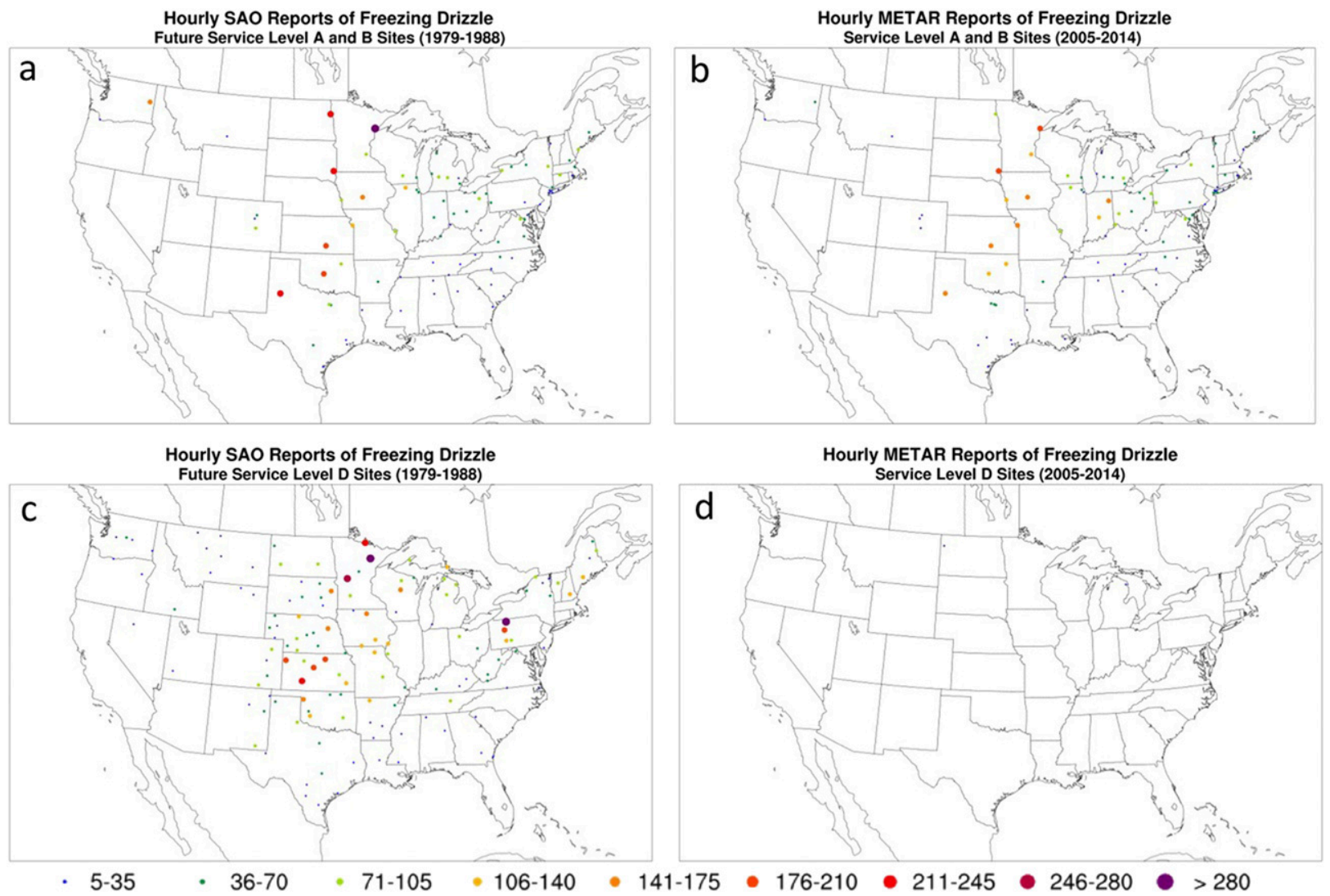

FIG. 12. Freezing drizzle reports by station for (a) the early decade at future service level A and B sites, (b) the later decade at service level A and B sites, (c) the early decade at future service level D sites, and (d) the later decade at service level D sites. 

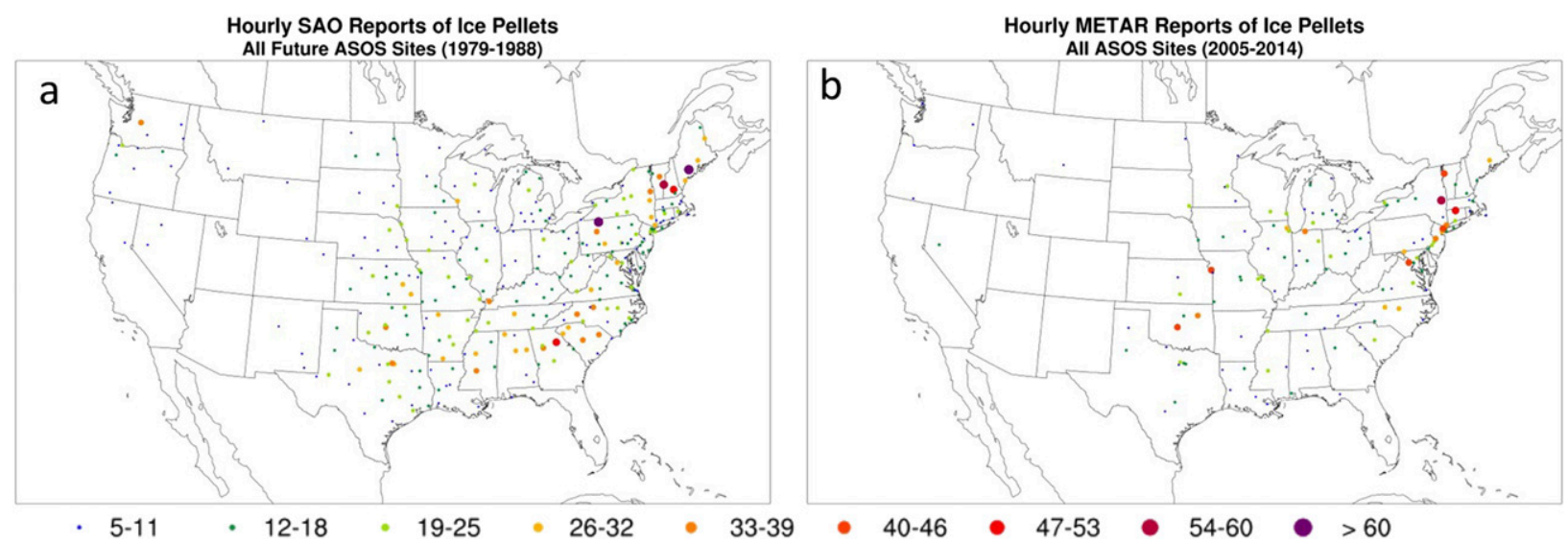

FIG. 13. (a) Number of ice pellet reports from SAO observations across the United States for the early decade from 1 Jan 1979 to 31 Dec 1988. (b) Number of ice pellet reports from METAR from across the United States for the later decade from 1 Jan 2005 to 31 Dec 2014.

where aircraft not certified for flight in freezing drizzle conditions could inadvertently attempt to fly or land in those conditions at these airports, unaware that freezing drizzle conditions exist. The results of such attempts could range from landing on an ice-covered runway to ice buildup on the aircraft inflight, resulting in performance degradation or an accident. Rasmussen et al. (2006) identified freezing drizzle as a hazard to aircraft ground deicing operations and numerous aircraft accidents have been attributed to flight in freezing drizzle conditions aloft [National Transportation Safety Board (NTSB) (NTSB 2007, 2011, 2018)]. While it can only be speculated as to the difference it might have made if the pilots had been aware they were flying into freezing drizzle, this information could have allowed them to divert to an alternative airport where these conditions did not exist, preventing the aircraft accident.

\section{f. Ice pellets}

Ice pellets present a unique challenge for this study as they rarely occur in pristine form and are more typically observed mixed with other types of precipitation (i.e., snow, rain, freezing rain, etc.). Only METARs of pristine ice pellets (PL) were used in this comparison. Ice pellets have the lowest observation rate of any of the other types of precipitation (over 4900 in the earlier decade and less than half in the later decade, indicating a decrease of over $56 \%$ ). Ice pellets present a hazard to aviation operations both aloft and at the surface. They indicate freezing rain conditions aloft, posing a significant hazard to aircraft in flight, and can adhere to an aircraft's surface on the ground, especially if mixed with other precipitation types (freezing rain, freezing drizzle, snow, etc.), posing a hazard to aircraft on the ground. Prolonged periods of ice pellets can suspend airport operations and overwhelm aircraft deicing activities
(Stoiber 2007). When comparing the two decades, it is clear that the areal coverage of ice pellets and the number of ice pellet reports decreased in the later decade due to the inability of the ASOS to detect and report them (Fig. 13).

The number of reports of ice pellets at service level A and $\mathrm{B}$ airports between decades was, again, similar (over 1350 in the earlier decade and nearly 1500 in the later decade). However, there appears to be a northward shift in the higher number of reports of ice pellets at service level A and B airports in the later decade (Fig. 14). Texas, Mississippi, Alabama, Georgia, and South Carolina all had between 30 and 50 reports in the earlier decade, but that number dropped by more than half in the later decade. Locations in the Midwest and along the Atlantic Seaboard all showed notable increases in ice pellet occurrences in the later decade. A similar trend was noted with freezing rain. Because the two precipitation types are often mixed together, the similarity between the trends is not surprising. As with freezing rain, the reasons for this northward shift in the later decade are not clear, though interannual weather variations could play a role as well as individual, highimpact weather events.

The removal of the human observers at the service level D airports has clearly had a significant impact on the climatological record for ice pellets. Over 1600 reports of ice pellets were observed in the earlier decade and only 25 reports were observed in the later decade even though the number of ASOS sites increased in the later decade. As stated earlier, service level D airports do not have human observers available to augment the observations and because the ASOS cannot report ice pellets, it is unknown how the 25 reports of ice pellets were generated at the service level D airports. Although ice pellet events occur infrequently, when they do occur, 

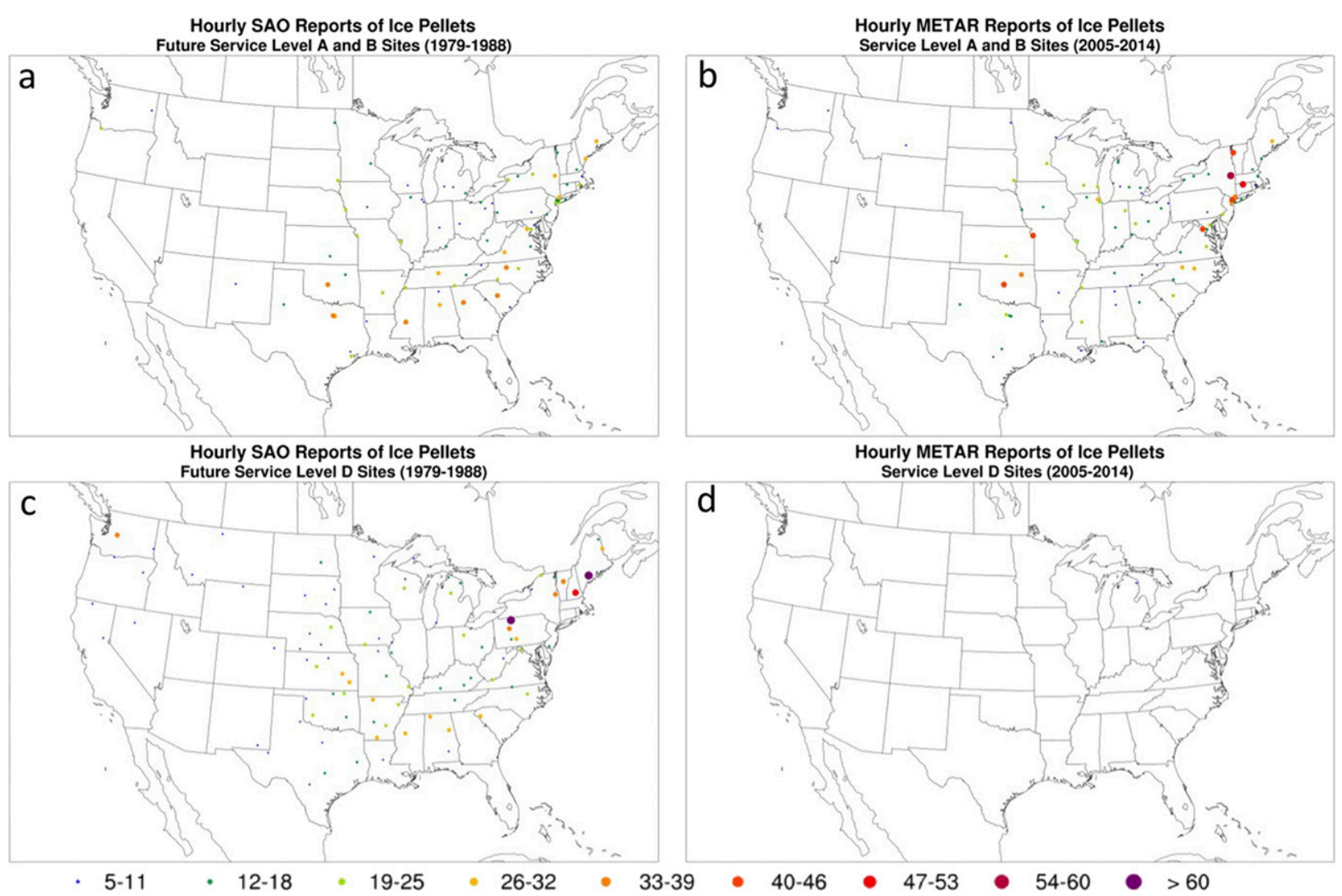

FIG. 14. Ice pellet reports by station for (a) the early decade at future service level A and B sites, (b) the later decade at service level A and B sites, (c) the early decade at future service level D sites, and (d) the later decade at service level D sites.

their impacts can be significant both to aircraft in flight and aircraft on the ground. This clearly demonstrates an area where improvements need to be made to the capability to detect ice pellets, particularly at service level D airports.

\section{Conclusions}

It is important to understand the impact that automation, such as ASOS, has had on the present weather reporting capabilities, both from a climatological perspective and an aviation perspective. It is also important to understand these impacts as many studies rely on precipitation-type reports to verify numerical model performance (Manikin et al. 2004; Manikin 2005; Wandishin et al. 2005; DeGaetano et al. 2008; Ikeda et al. 2013; Benjamin et al. 2016; Reeves et al. 2014) and improve radar hydrometeor classification algorithms (Elmore 2011; Schuur et al. 2012; Thompson et al. 2014; Tokay et al. 2018). These automation impacts, depending on the type of precipitation, have been shown to be both positive and negative.

One positive impact overall is an increase in the number of stations regularly reporting precipitation types that did not exist in the earlier decade, particularly at service level D locations. Another positive impact is the addition of precipitation-type reporting in the overnight hours at stations that were not staffed at all hours of the day and week in the earlier decade. Reports of rain and snow did not change significantly in areal extent, but there was a notable increase in the amount of rain reports in the northeast and snow reports in mountainous areas in the west. Observations of freezing rain also showed significant increases in reports in the later decade, particularly at service level D locations. This is attributable to the ASOS's automated and autonomous ability to detect ice accretion with the use of the icing sensor. Considering the hazard that freezing rain poses to aircraft operations, the ability to detect freezing rain conditions in an automated manner is a significant positive impact associated with automation.

Another notable positive impact is the relatively small change in the number of reports for all precipitation types, with the exception of drizzle, at service level A and B airports between decades. This indicates the methods for taking observations by humans has remained mostly consistent between the decades and 
suggests any climatological studies requiring accurate precipitation-type observations should focus on data from these airports.

A number of negative impacts were also noted with automation. Much of the decrease in drizzle reports at service level A and B airports is likely due to the separation of drizzle and mist as individually reportable phenomena when the United States adopted the METAR standard in the 1990s. This makes it difficult to assess the impact of automation on drizzle because the reporting criteria changed between the two decades. Reports of drizzle, freezing drizzle, and ice pellets significantly decreased in frequency in the later decade at service level D airports where the ASOS sites do not have the ability to report these conditions. The impacts on aviation at these airports, particularly for freezing drizzle and ice pellet precipitation types, are significant as these airports typically serve the general aviation sector and thus aircraft that are more susceptible to the dangers of flying, landing, or taking off in these conditions. The ASOS's inability to detect and report these weather types presents a real danger to aviation activities at these airports, but at the same time provides a clear guide to where improvements to automated weather observations need to be directed as the ASOS evolves in the future.

Acknowledgments. This research is in response to requirements and funding by the Federal Aviation Administration (FAA). The views expressed are those of the authors and do not necessarily represent the official policy or position of the FAA. NCAR is sponsored by the National Science Foundation. The authors acknowledge the support of James Riley of the FAA for his guidance, Victor Passetti of the FAA for his input and guidance, and Karen Slater of NCAR for her editing efforts.

\section{REFERENCES}

American Meteorological Society, 2013: Mist. Glossary of Meteorology, http://glossary.ametsoc.org/wiki/Mist.

Benjamin, S. G., J. M. Brown, and T. G. Smirnova, 2016: Explicit precipitation-type diagnosis from a model using a mixedphase bulk cloud-precipitation microphysics parameterization. Wea. Forecasting, 31, 609-619, https://doi.org/10.1175/ WAF-D-15-0136.1.

Cortinas, J. V., Jr., B. C. Bernstein, C. C. Robbins, and W. J. Strapp, 2004: An analysis of freezing rain, freezing drizzle, and ice pellets across the United States and Canada: 1976-90. Wea. Forecasting, 19, 377-390, https://doi.org/10.1175/1520-0434(2004)019<0377: AAOFRF $>2.0 . \mathrm{CO} ; 2$.

Dai, A., T. R. Karl, B. Sun, and K. E. Trenberth, 2006: Recent trends in cloudiness over the United States: A tale of monitoring inadequacies. Bull. Amer. Meteor. Soc., 87, 597-606, https://doi.org/10.1175/BAMS-87-5-597.
DeGaetano, A. T., B. N. Belcher, and P. L. Spier, 2008: Short-term ice accretion forecasts for electric utilities using the Weather Research and Forecasting Model and a modified precipitation-type algorithm. Wea. Forecasting, 23, 838-853, https://doi.org/10.1175/ 2008WAF2006106.1.

Doesken, N. J., T. B. McKee, and C. Davey, 2002: Climate data continuity-What have we learned from the ASOS Automated Surface Observing System. 13th Conf. on Applied Climatology, Portland, OR, Amer. Meteor. Soc., 2.7, https://ams.confex.com/ ams/pdfpapers/41337.pdf.

Elmore, K. L., 2011: The NSSL hydrometeor classification algorithm in winter surface precipitation: Evaluation and future development. Wea. Forecasting, 26, 756-765, https://doi.org/ 10.1175/WAF-D-10-05011.1.

- H. M. Grams, D. Apps, and H. D. Reeves, 2015: Verifying forecast precipitation type with mPING. Wea. Forecasting, 30, 656-667, https://doi.org/10.1175/WAF-D-14-00068.1.

FAA, 1989: Automated Weather Observing Systems (AWOS) applicability to far parts $121 \& 135$ Flt Ops. U.S. Dept. of Transportation Doc. 8000.69, 4 pp., https://www.faa.gov/ documentLibrary/media/Order/8000.69.pdf.

_ 2017: Surface weather observing. U.S. Dept. of Transportation Doc. JO 7900.5D, Change 1, https://www.faa.gov/ documentLibrary/media/Order/JO_7900.5D.pdf.

Free, M., and B. Sun, 2014: Trends in U.S. total cloud cover from a homogeneity-adjusted dataset. J. Climate, 27, 4959-4969, https://doi.org/10.1175/JCLI-D-13-00722.1.

Gall, R., K. Young, R. Schotland, and J. Schmitz, 1992: The recent maximum temperature anomalies in Tucson: Are they real or an instrumental problem? J. Climate, 5, 657-665, https://doi.org/ 10.1175/1520-0442(1992)005<0657:TRMTAI >2.0.CO;2.

Groisman, P. Ya., O. N. Bulygina, X. Yin, R. S. Vose, S. K. Gulev, I. Hanssen-Bauer, and E. Forland, 2016: Recent changes in the frequency of freezing precipitation in North America and northern Eurasia. Environ. Res. Lett., 11, 045007, https:// doi.org/10.1088/1748-9326/11/4/045007.

Guttman, N. B., and C. B. Baker, 1996: Exploratory analysis of the difference between temperature observations recorded by ASOS and conventional methods. Bull. Amer. Meteor. Soc., 77, 2865-2874, https://doi.org/10.1175/1520-0477(1996) 077<2865:EAOTDB $>2.0$. CO;2.

Ikeda, K., M. Steiner, J. Pinto, and C. Alexander, 2013: Evaluation of cold-season precipitation forecasts generated by the hourly updating High-Resolution Rapid Refresh model. Wea. Forecasting, 28, 921-939, https://doi.org/10.1175/ WAF-D-12-00085.1.

Kessler, R., L. Bosart, and R. Gaza, 1993: Recent maximum temperature anomalies at Albany, New York: Fact or fiction? Bull. Amer. Meteor. Soc., 74, 215-226, https://doi.org/10.1175/ 1520-0477(1993)074<0215:RMTAAA > 2.0.CO;2.

Kogan, F. N., 1995: Droughts of the late 1980s in the United States as derived from NOAA polar-orbiting satellite data. Bull. Amer. Meteor. Soc., 76, 655-668, https://doi.org/10.1175/1520-0477(1995) 076<0655:DOTLIT>2.0.CO;2.

Lin, X., and K. G. Hubbard, 2004: Sensor and electronic biases/errors in air temperature measurements in common weather station networks. J. Atmos. Oceanic Technol., 21, 1025-1032, https:// doi.org/10.1175/1520-0426(2004)021<1025:SAEEIA > 2.0.CO;2.

Manikin, G. S., 2005: An overview of precipitation type forecasting using NAM and SREF data. 21st Conf. on Weather Analysis and Forecasting/17th Conf. on Numerical Weather Prediction, Washington, DC, Amer. Meteor. Soc., 8A.6, https:// ams.confex.com/ams/pdfpapers/94838.pdf. 
_ type mini-ensemble for winter weather forecasting. 20th Conf. on Weather Analysis and Forecasting/16th Conf. on Numerical Weather Prediction, Seattle, WA, Amer. Meteor. Soc., 23.1, https://ams.confex.com/ams/pdfpapers/73517.pdf.

Namias, J., 1982: Anatomy of Great Plains protracted heat waves (especially the 1980 U.S. summer drought). Mon. Wea. Rev., 110, 824-838, https://doi.org/10.1175/1520-0493(1982)110<0824: AOGPPH $>2.0 . \mathrm{CO} ; 2$.

NCAR, 2018: METARS archive. NCAR Research Research Applications Laboratory, accessed 23 May 2018, https://ral.ucar.edu/ projects/winter/sites/metars.

NOAA, 1981: A guide to AMOS, RAMOS and AUTOB observations. National Weather Service Doc., 43 pp.

__ 1998: Automated Surface Observing System (ASOS) user's guide. National Weather Service Doc., 61 pp., https:// www.weather.gov/media/asos/aum-toc.pdf.

__ 2019: Automated Surface Observing System (ASOS) archive. NCEI, accessed 3 April 2019, https://www.ncdc.noaa.gov/ data-access/land-based-station-data/land-based-datasets/ automated-surface-observing-system-asos.

NTSB, 2007: Crash during approach to landing, Circuit City Stores, Inc., Cessna Citation 560, N500AT, Pueblo, Colorado, February 16, 2005. NTSB Aircraft Accident Rep. NTSB/AAR-07/02, 86 pp., https://www.ntsb.gov/investigations/AccidentReports/ Reports/AAR0702.pdf.

__ 2011: Crash during approach to landing, Empire Airlines Flight 8284, Avions de Transport Régional Aerospatiale Alenia ATR 42-320, N902FX, Lubbock, Texas, January 27, 2009. NTSB Aircraft Accident Rep. NTSB/AAR-11/02, 128 pp., https:/www.ntsb.gov/investigations/AccidentReports/ Reports/AAR1102.pdf.

__, 2018: Crash during approach to landing, BRYK STEVEN L VELOCITY XL RG, N787SB, Santa Fe, New Mexico, January 15, 2018. NTSB Aircraft Accident Rep. NTSB/ CEN18LA077, https://www.ntsb.gov/_layouts/ntsb.aviation/ brief.aspx?ev_id=20180117X23437.

Perkey, D. J., K. N. Young, and C. W. Kreitzberg, 1983: The 1980-81 drought in eastern Pennsylvania. Bull. Amer. Meteor. Soc., 64, 140-147, https://doi.org/10.1175/1520-0477(1983) 064<0140:TDIEP $>2.0$. CO;2.

Rasmussen, R., and Coauthors, 2006: New ground deicing hazard associated with freezing drizzle ingestion by jet engines J. Aircr., 43, 1448-1457, https://doi.org/10.2514/1.20799.
Reeves, H. D., 2016: The uncertainty of precipitation-type observations and its effect on the validation of forecast precipitation type. Wea. Forecasting, 31, 1961-1971, https://doi.org/10.1175/ WAF-D-16-0068.1.

— K. L. Elmore, A. Ryzhkov, T. Schuur, and J. Krause, 2014: Source of uncertainty in precipitation-type forecasting. Wea. Forecasting, 29, 936-953, https://doi.org/10.1175/WAF-D-14-00007.1.

Schuur, T. J., H. Park, A. V. Ryzhkov, and H. D. Reeves, 2012: Classification of precipitation types during transitional winter weather using the RUC model and polarimetric radar retrievals. J. Appl. Meteor. Climatol., 51, 763-779, https://doi.org/10.1175/ JAMC-D-11-091.1.

Stoiber, J., 2007: Region shifts to normal (sort of). Philadelphia Enquirer, accessed 20 November 2019, https://www.inquirer.com/ philly/news/local/20070318_Region_shifts_to_normal_sort_ of_.html.

Sun, B., C. B. Baker, T. R. Karl, and M. D. Gifford, 2005: A comparative study of ASOS and USCRN temperature measurements. J. Atmos. Oceanic Technol., 22, 679-686, https://doi.org/ 10.1175/JTECH1752.1.

_ - T. R. Karl, and D. J. Seidel, 2007: Changes in cloud-ceiling heights and frequencies over the United States since the early 1950s. J. Climate, 20, 3956-3970, https://doi.org/10.1175/ JCLI4213.1.

Thompson, E. J., S. A. Rutledge, B. Dolan, V. Chandrasekar, and B. L. Cheong, 2014: A dual-polarization radar hydrometeor classification algorithm for winter precipitation. J. Atmos. Oceanic Technol., 31, 1457-1481, https://doi.org/ 10.1175/JTECH-D-13-00119.1.

Tokay, A., B. Swick, and J. Villegas Bravo, 2018: Comparison of precipitation phase algorithms: A ground validation study for GPM. 2018 Fall Meeting, Washington, DC, Amer. Geophys. Union, Abstract H43F-2483.

Wandishin, M. S., M. E. Baldwin, S. L. Mullen, and J. V. Cortinas Jr., 2005: Short-range ensemble forecasts of precipitation type. Wea. Forecasting, 20,609-626, https://doi.org/10.1175/ WAF871.1.

Warren, S. G., R. M. Eastman, and C. J. Hahn, 2007: A survey of changes in cloud cover and cloud types over land from surface observations, 1971-96. J. Climate, 20, 717-738, https://doi.org/ 10.1175/JCLI4031.1.

Weisman, R. A., 1985: The 1980-81 drought in southeastern New York. Bull. Amer. Meteor. Soc., 66, 788-794, https://doi.org/10.1175/ 1520-0477(1985)066<0788:TDISNY>2.0.CO;2. 